Pacific Journal of Mathematic 


\section{A CO-TOPOLOGICAL APPLICATION TO MINIMAL SPACES}

GiovanNI VigLino

A space $(X, \tau)$ which satisfies a topological property $P$ is said to be minimal- $P$ if $T=\left\{\tau^{\prime} \mid \tau^{\prime}\right.$ is a $P$-topology on $X$; $\left.\tau^{\prime} \lesseqgtr \tau\right\}=\varnothing$. For example, a Hausdorff space $(X, \tau)$ is minimal Hausdorff if there exists no Hausdorff topology on $X$ which is strictly weaker than $\tau$. The purpose of this paper is to show that for certain properties one need only consider a subset of $T$ " induced" by $\tau$ to determine if $(X, \tau)$ is minimal- $P$.

Notation. Let $\beta$ be an open base for the space $(X, \tau)$. $\tau_{\beta}$ will denote the topology on $X$ generated by the subbase $\left\{X \backslash C l_{\tau} B \mid B \in \beta\right\}$.

REMARK. J. de Groot in his investigation for a general classification of Baire spaces considered the above topologies (cf. [1], [4]). These topologies have come to be known as co-topologies.

Definitions. A filter base is regular if it is open and equivalent to a closed filter base.

A filter base $\mathscr{U}$ is Urysohn if for each nonadherent point $a$, there exists a neighborhood $V$ and $G \in \mathscr{U}$ such that $\mathrm{Cl}_{\tau} V \cap \mathrm{C} l_{\tau} G=\varnothing$.

REMARK. In this paper, the Bourbaki convention for the topological separation properties will be observed; specifically, all spaces are assumed to be Hausdorff.

The proof of the following lemmas are left to the reader. A proof for the regular case of Lemma 1 is similar to the proof of Theorem 2 in [3].

LEMMA 1. Let $(X, \tau)$ be a Hausdorff (Urysohn; regular) space; let $\mathscr{Z}=\left\{U_{\alpha}\right\}_{\alpha \in A}$ be a nonconvergent open (Urysohn; regular) filter base with unique adherent point $x_{0}$; let $\beta=. \mathscr{V} \cup$.ll where

$$
\mathscr{N}=\left\{N \mid N \in \tau \text { and } x_{0} \in \mathrm{Cl} l_{\tau} N\right\}
$$

and

$$
\mathscr{l l}=\left\{M \mid M \in \tau \text { and } M \subset X \backslash \mathrm{C} l_{\tau} U_{\alpha} \text { for some } \alpha \in A\right\}
$$

Then (i) $\beta$ is a base for $\tau$; and

(ii) $\tau_{\beta}$ is a Hausdorff (Urysohn; regular) topology strictly 
weaker than $\tau$.

Lemma 2. Let $(X, \tau)$ be a normal (completely normal) space; let $\mathscr{Q}$ be a nonconvergent regular filter base with unique adherent point $x_{0}$; let $\beta$ be defined as in Lemma 1. Then $\tau_{\beta}$ is a normal (completely normal) topology strictly weaker than $\tau$.

In the following theorem $P$ denotes any of the following properties: (i) Hausdorff, (ii) Urysohn, (iii) regular, (iv) completely regular, (v) normal, (vi) completely normal, (vii) locally compact. In [2], [3], [5] it is shown that there exist minimal Hausdorff, minimal Urysohn, and minimal regular spaces which are not compact, while for properties (iv) through (vii) mininal- $P$ is equivalent to compactness.

Theorem. A P-space $(X, \tau)$ is minimal-P if and only if $\left\{\tau_{\beta} \mid \tau_{\beta}\right.$ is $\left.P ; \tau_{\beta} \neq \tau\right\}=\varnothing$. $^{1}$

Proof. Necessity, in each case, follows from the fact that $\tau_{\beta} \leqq \tau$ for every open base $\beta$.

Sufficiency for property (i) through (iii): Suppose $(X, \tau)$ is not minimal Hausdorff (Urysohn; regular). Then there exists an open (Urysohn; regular) filter base $\mathscr{C}=\left\{U_{\alpha}\right\}_{\alpha \in A}$ with uniques adherent point $x_{0}$, which does not converge (see [5], [2]). By Lemma 1, there exists a base $\beta$ for $\tau$ such that $\tau_{\beta} ફ \tau$ and $\tau_{\beta}$ is Hausdorff (Urysohn; regular).

Sufficiency for completely regular': Suppose $^{2}(X, \tau)$ is not compact.

Let $\left(Y, \tau^{\prime}\right)$ denote a compact extension of $(X, \tau)$. Take and fix $p \in Y \backslash X$. Let $\mathscr{S}$ be the filter base of open neighborhoods of $p$, and $\mathscr{S}^{*}$ denote the trace of $\mathscr{S}$ in $X$. Considered as a filter base in $\left(Y, \tau^{\prime}\right), \mathscr{S}^{*}$ has a unique adherent point, namely $p$. Thus $\mathscr{L}^{*}$ has no adherent point in $(X, \tau)$. Fix and element $x_{0}$ in $X$. Let $\beta=\mathscr{N} \cup \mathscr{C}$ where $\mathscr{N}=\left\{N \mid N \in \tau\right.$ and $\left.x_{0} \in \mathrm{Cl}_{\tau} N\right\}$ and $\mathscr{C l}=\{M \mid M \in \tau$ and $M \subset X \backslash C l_{\tau} S^{*}$ for some $\left.S^{*} \in \mathscr{S}^{*}\right\}$. One can show $\beta$ is an open base for $\tau$. Similarly one can show that $\mathscr{K}=\left\{\mathrm{X} / \mathrm{C} l_{\tau} H \mid H \in \mathscr{N} \cup \mathscr{C}\right\}$ is a base for $\tau_{\beta}$.

We will now show that $\tau_{\beta} \neq \tau$ and $\left(X, \tau_{\beta}\right)$ is completely regular. Let us first note that since $(X, \tau)$ is regular and since $\mathscr{N} \subset \beta$, then $G \in \tau_{\beta}$ whenever $G \in \tau$ and $x_{0} \notin G$. Hence if $f$ is continuous on $(X, \tau)$ then $f$ is continuous everywhere on $\left(X, \tau_{\beta}\right)$ except possibly at $x_{0}$. Now there exists $S^{*} \in \mathscr{S}^{*}$ such that $x_{0} \notin \mathrm{Cl} l_{\tau} S^{*}$. Since $\tau$ is regular, then there exists $U \in \tau$ such that $x_{0} \in U$ and $C l_{\tau} U \cap C l_{\tau} S^{*}=\varnothing$. Since any element of $\tau_{\beta}$ which contains $x_{0}$ must meet $S^{*}$, then $U \notin \tau_{\beta}$. Thus

${ }^{1}$ The result for $p=$ Hausdorff was independently obtained by G. Strecker.

2 The technique used by Berri in [2] to show that a space is compact if it is minimal completely regular is extensively used in this proof. 
$\tau_{\beta} \neq \tau$

We complete the proof by showing $\tau_{\beta}$ is completely regular. Take $b \in X$ and $X \backslash \mathrm{Cl} l_{\tau} H \in \mathscr{Y}$ where $b \notin X \mid C l_{\tau} H$ and $H \in \mathscr{N} \cup \mathscr{C l}$. We wish to show there exists a continuous, real-valued function $f$ on $\left(X, \tau_{\beta}\right)$, such that $f(b)=1$ and $f(x)=0$ for all $x \in \mathrm{Cl}_{\tau} H$. Suppose $H \in \mathscr{N}^{\text {. Then }} x_{0} \in \mathrm{C} l_{\tau} H$. Let $S^{*} \in \mathscr{S}^{*}$ be such that $b \notin \mathrm{Cl}_{\tau} S^{*}$; Since $(X, \tau)$ is regular, then there exists $V \in \tau$ such that $b \in V$ and

$$
\mathrm{C} l_{\tau} V \cap \mathrm{Cl}\left(H \cup S^{*}\right)=\varnothing \text {. }
$$

Since $(X, \tau)$ is completely regular, then there exists a continuous, real-valued function $f$ such that $f(b)=1$ and $f(x)=0$ for all $x \in X \backslash V$. By a previous remark, $f$ is continuous at every point of $\left(X, \tau_{\beta}\right)$ except possibly at $x=x_{0}$. We will now show $f$ is continuous at $x=x_{0}$. Now for all $x \in X \backslash V, f(x)=0$. Since $C l_{\tau} V \cap \mathrm{C} l_{\tau}\left(H \cup S^{*}\right)=\varnothing$, then $f(x)=0$ for all $x \in X \backslash \mathrm{Cl} l_{\tau} V$. Thus $f$ is continuous at all $x \in X \backslash \mathrm{Cl} l_{\tau} V$, and hence at all $x \in \mathrm{Cl}_{\tau}\left(H \cup S^{*}\right)$. Therefore $f$ is continuous at $x_{0}$.

Similarly one can show that if $H \in \mathscr{C l}$, then there exists a realvalued continuous function $f$ on $\left(X, \tau_{\beta}\right)$ such that $f(b)=1$ and $f(x)=0$ for each $x \in \mathrm{C} l_{\tau} H$.

Sufficiency for properties (v) and (vi): Suppose the normal (completely normal) space $(X, \tau)$ is not compact. Then $X$ is not minimal regular since a minimal regular normal (completely normal) space is minimal completely regular. Hence there exists a nonconvergent regular filter base $\mathscr{C}$ with a unique adherent point $x_{0}$. By Lemma 2, there exists a base $\beta$ for $\tau$ such that $\tau_{\beta} \lesseqgtr \tau$ and $\tau_{\beta}$ is normal (completely normal).

Sufficiency for locally compact: Suppose $(X, \tau)$ is not minimal locally compact (i.e., not compact). Let $\left(Y, \tau^{\prime}\right)$ denote the Alexandroff compactification of $X$ with $Y=X \cup\{p\}$ where $p \notin X$. Fix an element $x_{0}$ in $X$ and construct $\beta=\mathscr{N} \cup \mathscr{C}$ as in the proof of sufficiency for completely regular spaces. One can show $\tau_{\beta} \lesseqgtr \tau$ and $\tau_{\beta}$ is locally compact, and in fact, compact.

\section{REFERENCES}

1. J. Aarts and J. de Groot, et al., Colloquium co-topologie, Mathematisch Centrum (Amsterdam), syllabus zwA, 1964.

2. M. P. Berri, Minimal topological spaces, Trans. Amer. Math. Soc. 108 (1963), 97105.

3. M. P. Berri, and R. Sorgenfrey, Minimal regular spaces, Proc. Amer. Math. Soc. 14 (1963), 454-458.

4. J. de Groot, Subcompactness and the Baire category theorem, Nederl. Akad. Wetensch. Indag. Math. 25 (1963), 761-767.

5. H. Herrlich, $T_{\nu}$-Abgeschlossenheit und $T_{\nu}$-Minimalität, Math. Zeitschr. 88 (1965), 285-294. 
Received August 23, 1967, and in revised form October 20,1967. Some of the results in this paper appear in the author's doctoral dissertation written under the supervision of Professor Robert McDowell at Washington University.

WASHINGTON UNIVERSity, St. Louis, Missouri

Wesleyan University, Middletown, Connecticut 


\section{PACIFIC JOURNAL OF MATHEMATICS}

EDITORS

H. ROYDEN

Stanford University

Stanford, California

R. R. Phelps

University of Washington

Seattle, Washington 98105
J. DugundJI

Department of Mathematics

University of Southern California

Los Angeles, California 90007

\section{RICHARD ARENS}

University of California

Los Angeles, California 90024

\section{ASSOCIATE EDITORS}
E. F. BeCKENBACH
B. H. NeUmanN
F. WOLF
K. YOSIDA

\section{SUPPORTING INSTITUTIONS}

UNIVERSITY OF BRITISH COLUMBIA CALIFORNIA INSTITUTE OF TECHNOLOGY UNIVERSITY OF CALIFORNIA MONTANA STATE UNIVERSITY UNIVERSITY OF NEVADA NEW MEXICO STATE UNIVERSITY OREGON STATE UNIVERSITY UNIVERSITY OF OREGON OSAKA UNIVERSITY UNIVERSITY OF SOUTHERN CALIFORNIA
STANFORD UNIVERSITY UNIVERSITY OF TOKYO UNIVERSITY OF UTAH WASHINGTON STATE UNIVERSITY UNIVERSITY OF WASHINGTON

AMERICAN MATHEMATICAL SOCIETY CHEVRON RESEARCH CORPORATION TRW SYSTEMS NAVAL WEAPONS CENTER 


\section{Pacific Journal of Mathematics \\ Vol. 27, No. $1 \quad$ January, 1968}

Willard Ellis Baxter, On rings with proper involution ............... 1

Donald John Charles Bures, Tensor products of $W^{*}$-algebras........... 13

James Calvert, Integral inequalities involving second order derivatives . . . . 39

Edward Dewey Davis, Further remarks on ideals of the principal class.... 49

Le Baron O. Ferguson, Uniform approximation by polynomials with integral

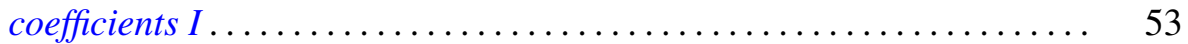

Francis James Flanigan, Algebraic geography: Varieties of structure

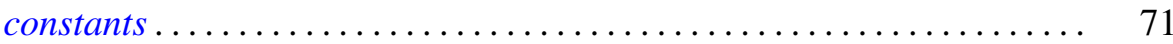

Denis Ragan Floyd, On QF -1 algebras ..................... 81

David Scott Geiger, Closed systems of functions and predicates ......... 95

Delma Joseph Hebert, Jr. and Howard E. Lacey, On supports of regular Borel measures ................................... 101

Martin Edward Price, On the variation of the Bernstein polynomials of a function of unbounded variation ........................ 119

Louise Arakelian Raphael, On a characterization of infinite complex matrices mapping the space of analytic sequences into itself........ 123

Louis Jackson Ratliff, Jr., A characterization of analytically unramified

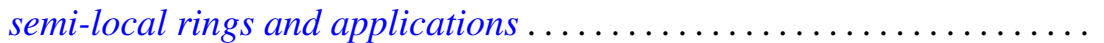

S. A. E. Sherif, A Tauberian relation between the Borel and the Lototsky transforms of series ................................ 145

Robert C. Sine, Geometric theory of a single Markov operator .......... 155

Armond E. Spencer, Maximal nonnormal chains in finite groups......... 167

Li Pi Su, Algebraic properties of certain rings of continuous functions .... 175

G. P. Szegô, A theorem of Rolle's type in $E^{n}$ for functions of the class $C^{1} \ldots 193$

Giovanni Viglino, A co-topological application to minimal spaces ........ 197

B. R. Wenner, Dimension on boundaries of $\varepsilon$-spheres ............... 201 